\title{
EL IMPUESTO A LA RENTA EN LA COMUNIDAD LABORAL *
}

\section{ANALISIS DE LA RENTA COMUNITARIA}

\section{Cuestiones previas}

La Comunidad Laboral implica como sistema de participación la percepción de beneficios comunitarios, es decir de réditos producidos o generados por causa de la existencia y desarrollo de esta nueva institución, por ello a tales ingresos se les denomina "comunitarios".

El concepto "renta comunitaria" significa pues el conjunto de réditos que se perciben dentro del sistema indicado. Un análisis de la renta comunitaria deierminará el contenido, las categorias y la atribución de los réditos a quien constituye el sujeto pasivo del impuesto según el sistema vigente o el que proponemos.

Para analizar y aplicar sobre "la renta comunitaria" el régimen tributario referente al impuesto que nos ocupa tenemos necesariamente que revisar conceptos básicos en doctrina, especialmente sobre el sujeto pasivo, puesto que tratándose de este impuesto directo y personal es imprescindible contar a efectos de la investigación analítica con las características, clases, etc., que se establecen en la doctrina respecto al sujeto pasivo.

El enfoque principal de esta revisión en doctrina versará, principalmente, sobre las clases de sujeto pasivo a fin de obtener una noción precisa que permita dilucidar si es posible tratar a la Comunidad Laboral como un sujeto pasivo en la relación jurídico-tributaria respecto al impuesto a la renta.

iniciaremos entonces este trabajo con un breve estudio de los elementos fundamentales de la relación juridico-tributaria, a fin de establecerlos nítidamente en

* Extracto de la tesis presentada por el autor para optar el grado de Bachiller en Derecho en mayo de 1973. relación a nuestro tema, obteniendo el concepto de sujeto pasivo en doctrina, para luego proseguir con la critica e investigación del sistema aplicable a la renta comunitaria de conformidad con el régimen vigente, el cual es adaptado en su aplicación a esta nueva situación jurídica y social que en el aspecto impositivo ofrece uno de los más complejos panoramas.

\section{ELEMENTOS DE LA RELACION JURIDICO-TRIBUTARIA}

Siguiendo en esta parte a Berliri (1), debemos distinguir los conceptos fundamentales que permitirán el análisis correcto de este tema. Sabemos que en el Derecho Tributario se presentan los conceptos obligación tributaria y relación jurídico-tributaria o impositiva. La obligación tributaria, como señala el autor, es el género de la que forman parte varias clases de obligaciones y no sólo la pecuniaria que suele ser la más importante económicamente hablando. De tal modo, debemos tener presente que la obligación tributaria puede o no darse en las relaciones jurídicas contempladas por las normas tributarias, y que dentro de la relación jurídico-impositiva, la obligación tributaria constituye el núcleo central de ella, es decir está implícita, actual o potencialmente dentro de ella.

Debemos entender por obligación tributaria la prestación a cargo del sujeto pasivo y a favor del sujeto activo, con la cual enriquece el segundo a costa del primero, distinguiendo así la obligación tributaria de otras obligaciones reguladas por la ley tributaria. Por otra parte, como ya se ha dicho, la obligación tributaria se encuadra siempre dentro de la relación juridico-impositiva, aunque esta relación específica es más compleja, pues en ella no sólo se da la obligación

1. BERLIRI, Antonio. Principios de derecho tributario, Vol. II, Madrid, Editorial de derecho financiero, 1971. 
tributaria, sino otras relaciones jurídicas, deberes y derechos de sujetos distintos a los sujetos de la obligación tributaria. Por ello, la definición del profesor italiano sobre relación jurídico-impositiva:

"Una relación compleja producto de la unión de diversas obligaciones tributarias actuales o eventuales, a favor de un mismo sujeto activo, que derivan directa o indirectamente de una determinada situación base o de los distintos derechos, potestades o prohibiciones ligados a las mismas" (2)

nos permite apreciar que la relación juridico-impositiva conlleva siempre la posibilidad de una obligación tributaria, la que deriva directa o indirectamente del hecho imponible, del ejercicio del derecho potestativo a favor del fisco o podrá surgir de un deber impuesto del que a su vez, nacerá obligación tributaria o derecho potestativo.

Los elementos de la obligación tributaria son la relación jurídica, los sujetos de dicha relación y el objeto de la misma.

El vinculo jurídico tiene como fuente la ley exclusivamente. Por ello, la obligación nace con independercia de las voluntades de los sujetos que intervienen, siendo de idéntica naturaleza la obligación ex lege de derecho privado.

Dentro del tema sobre el vínculo jurídico, como elemento de la obligación tributaria, se suscita el problema de la causa, cuya existencia y concepción son moivo de extensa polémica entre los autores; pero es conveniente, soslayando la polémica, expresar que existen dos acepciones genéricas de causa en la relación jurídico-tributaria, la de causa primera, como la que se refiere al fin público que justifica la imposición (la ratio legis de la norma) y una segunda acepción como causa inmediata, que significa la menor o mayor capacidad contributiva del contribuyente. La primera acepción se considera en gran parte de la doctrina como fundamento propiamente dicho de la potestad tributaria, pero que no puede hablarse en esie sentido de la causa de la obligación tributaria. En cambio, la segunda acepción se admite como presupuesto para el nacimiento de la obligación tributaria; así se señala que la causa constituye únicamente el hecho jurídico previsto por el legislador para que sur-

2. Idem, página 130 . ja la obligación tributaria, asi el presupuesto de hecho sería para algunos autores la causa de la obligación tributaria, lo que equivale a identificar el concepio de causa con el concepto de presupuesto de hecho, o sea la percepción de un ingreso, la de una renta, la fabricación o la venta de mercancías, la adquisición, el consumo, etc.

Otros autores (3) opinan que no basta el supuesto de hecho sino también otro elemento que sería la voluniad de las partes, el fin del negocio jurídico, la función económico-social del mismo, etc. De todo ello, se desprende que el concepto de causa como fuerte de la obligación se circunscribe a las obligaciones de carácter contractual, y asi no podría hablarse de causa jurídica en la obligación tributaria cuando ésta no tenga como presupuesto el negocio jurídico, o sea que la fuente de la obligación tributaria provenga de un contrato.

En torno a la causa de la relación jurídica, Berliri la identifica como fuente de la obligación o presupuesto de hecho, considerado innecesario admitir el concepto de causa en otros sentidos (4). Sin embargo, muchos autores se ocupan amplia y profundamente de este concepto en el sentido de justificación, fundamento o nexo causal de la obligación tributaria. Creemos por nuestra parte que la extensión sobre este punto rebasa los alcances y fines de la presente tesis, concretándonos a señalar que compartimos el criterio de Amorós (5), quien sostiene la procedencia de admitir el elemento causa no sólo para los supuestos anotados, sino también la existencia de tributos causales y afirma que doctrinariamente el problema de la causa se traduce en el problema de la fuenie de las obligaciones.

\section{a) Sujeto activo}

El segundo elemento de la obligación tributaria está constituido por los sujetos entre los que se produce el vínculo jurídico, los que se determinan sujeto activo, o acreedor, y sujeto pasivo, o deudor. El acreedor tributario generalmente son los entes públicos, con

3. Griziotti, Ranelleti, Publiese, Jarach, Vanoni y Blumestein.

4. BERLIRI, Antonio. Principios de derecho tributario, Vol. II, Madrid, Editorial de derecho financiero, 1971 , página 180 .

5. Idem, página 203, notas al vínculo jurídico de Narciso Amorós Rica. 
o $\sin$ potestad tributaria, y también pueden serlo los llamados auxiliares del ente público. El problema de la determinación de sujeto activo se resuelve cuando no esté expresamente indicado en la ley tributaria por la atribución implícita del objeto de la obligación, a favor de uno u otro ente, de acuerdo a las caracteristicas del hecho generador del tributo. Como sabemos, el sujeto activo en la obligación tributaria es aquel ente de los ya indicados, que, conforme a la norma tributaria, tiene la titularidad del crédito.

\section{b) Sujeio pasivo}

Sobre la determinación del sujeto pasivo, Berliri impugna los criterios de Pugliese y Tesoro (6), en cuanto que son relevantes para la identificación del sujeto pasivo, caracteres tales como: la naturaleza, estado, profesión, nacionalidad, religión, edad, sexo, etc., atribuyendo estas características a la determinación del presupuesto de hecho, o sea características específicas del hecho imponible, pero nunca referentes a la teoria de los sujetos de la obligación tributaria.

En opinión de Berliri, el sujeto pasivo se determina por el carácter de deudor del impuesto, y éste se define como aquél que está obligado a entregar el objeto de la obligación tributaria al acreedor, no considerardo, pues, sujeto pasivo a quien únicamente está obligado a reeembolsar al deudor, o a quien está obligado a la prestación por obligación diversa, como es el caso del flador o garante. Sin embargo, admite el carácter de sujeto pasivo de la obligación tributaria para el obligado como sustituto, este sujeto se distingue del deudor sustituido en tener una acción de regreso a efectos de resarcirse de la prestación a la que está obligado frente al acreedor. Es a este sujeto que le reconoce la calidad de sujeto pasivo, al igual que el deudor del tributo, en razón de que el sustituto está relacionado con el hecho imponible. La ley le reconoce un derecho de reembolso, como ya hemos dicho, y está determinado en la norma tributaria. Añadiremos que el sustituto puede ser parcial o total en la obligación.

Se señala como otra figura de sujeto pasivo al responsable, es decir al sujeto que está obligado junto a otro del que puede repetir lo pagado. El autor que citamos considera impropio atribuirle la calidad de sujeto pasivo, indicando que los responsables de la pres-

\section{Idem, página 208 .}

tación jamás lo son por deuda propia, ni en parte ni en todo, y que la responsabilidad frente al acreedor deviene o de una relación personal con el deudor o de una relación con la cosa que es tomada en consideración por la norma tributaria para determinar la obligación.

En la relación juridica de la obligación tributaria, además de los sujetos vinculados directamente por ella, podemos encontrar en algunos casos los llamados "entes de hecho", pero que a pesar de tal derominación, debemos también considerarlos como sujetos pasivos con capacidad plena o capacidad limitada cuando está expresamente atribuida o reconocida por la norma tributaria en los casos de persona colectiva o colectividad de intereses, que normalmente no reviste los caracteres típicos de persona jurídica. Todo deudor de una prestación tributaria tiene, pues, que ser reconocido en su capacidad para ser titular del derecho sobre el patrimonio o la renta objeto de la obligación tributaria.

Por esto, además de otras razones (7), consideramos que en el caso de la Comunidad Laboral no se podría hablar de "ente de hecho" con calidad de sujeto pasivo puesto que para serlo se requiere fisonomía jurídica distinta a la de persona moral, como Ic es la Comunidad Laboral.

\section{c) El objeto del impuesto}

Cuando se habla del objeto de la obligación tribularia, la doctrina distingue del concepto de prestación, como el contenido de la obligación, del bien o la cosa que vendría a ser el objeto de esta prestación.

Dentro del concepto, prestación, se les clasifica como positivas y negativas, y las primeras se traducen en obligaciones de dar y de hacer, considerándose que constituye auténtica obligación tributaria la de dar, teniendo en cuenta que ésta consiste en un traspase de riqueza desde el patrimonio del contribuyente al del sujeto activo. En cuanto a la prestación de hacer, se discute si ésta es de naturaleza tributaria equivalente a la de dar, señalándose que en algunos casos es un medio de cumplir la prestación pecuniaria y ésta sería la obligación de hacer especificamente tributaria, mientras que otras prestaciones de hacer ten-

7. La naturaleza jurídica sui generis de esta institución no permite la analogía con los conceptos "persona colectiva" o "colectividad de intereses". 
drian el carácter de accesorias de la prestación de dar, o sea que son deberes positivos que tienden a verificar el pago, con el cual se cumple la obligación tributaria. Es importante señalar adicionalmente que dentro de las prestaciones de dar, el pago puede ser en dinero o entregando otra cosa, y en lo relativo a las obligaciones de hacer, se distingue que, cuando la ley impone una prestación personal que puede ser suslituida por una prestación de dar, es esta última la que se estima como auténtica obligación tributaria.

Sobre las prestaciones negativas como un no hacer por parte del sujeto pasivo, se les atribuye más bien el carácter de limitaciones a la libertad particular y no una obligación en el sentido de obligación tributaria propiamente dicha.

\section{LA RENTA DE LA COMUNIDAD LABORAL}

En esta parte toca analizar e interpretar el régimen impositivo vigente sobre la llamada renta comunitaria. Para ello, debemos determinar, dada la especial y nueva situación, si este nuevo ente está considerado como sujeto pasivo en la obligación tributaria, y esto incluye analizar si la renta comunitaria es atribuible a ella y/o a sus miembros.

\section{a) Caracteres}

Se trata aquí de determinar si este nuevo ente puede ser considerado sujeto pasivo en la relación juridico-tributaria en lo que al impuesto en cuestión se refiere (8).

8. Como se sabe, el sistema tributario de imposición a los réditos establece dos impuestos a la renta; uno, a las personas naturales, el otro a las personas jurídicas. Nos referimos, pues, al impuesto que recae sobre las rentas de estas últimas.

"Si los réditos de Tercera Categoría son obtenidos por sociedades de capital dichos réditos se atribuyen a las sociedades mismas que son contribuyentes con carácter definitivo, en la forma que la ley expresamente establece para ellas. En otra palabras, el impuesto a los réditos sobre las sociedades de capital grava el rédito de la Tercera Categoría que estas sociedades obtienen en forma separada y distinta del impuesto a los réditos correspondientes a las personas físicas y sucesiones indivisas que obtienen réditos de la misma categoría a través de empresas unipersonales o de sociedades de personas, incluyendo entre ellas las de responsabilidad limitada".

Dino Jarach, citado en Impuesto a la Renia, Tomo I, Capítulo 2, página 297 de Luis Carlos Rodrigo M.
La legisiación tributaria sobre los impuestos a la renta establece un concepto especial de persona jurídica, determinando que entre los diversos tipos de personas morales que existen en el derecho peruano, únicamente aquéllas que el Decreto señala como "personas juridicas" revisten el carácter de sujetos pasivos del impuesto a la renta de personas jurídicas. En el Capitulo III del referido Decreto Supremo, se establece quién será considerado como persona jurídica para los efectos del impiesto, siendo, por cierto, la enunciación del artículo 14 ํ taxativa.

Los requisitos que exige tal dispositivo para consjderar a un ente moral sujeto del impuesto dentro del marco territorial, es decir reíerido sólo a contribuyentes domiciliados, son esencialmente:

1.-Que la persona moral sea empresa y su patrimonio sea constituido por aportes dinerarios que que manifiesten en acciones, o sea lo que se entiende por sociedades de capital.

2.-Que, como única excepción al criterio anterior, se trate de rentas no exoneradas percibidas por asociaciones, cooperativas y fundaciones, las que por su naturaleza jurídica no tienen fines de lucro.

De los requisitos mencionados se desprende que para que una persona moral pueda ser sujeto del impuesto a la renta soive "personas jurídicas" debe estar organizada como empresa y el manejo de la misma en razón del capital social, representado por acciones mercantiles.

Confrontada la Comunidad con el criterio de la ley tributaria citada, no reúne los requisitos que la revisten con el carácter de sujeto pasivo en el impuesto a las personas jurídicas, pues, como se ha visto en el primer capitulo, no tiene fines de lucro mercantil, no está organizada como empresa ni ejerce ella misma actividades de Tercera Categoria; desempeña más bien el papel de administradora y mandataria de los bienes e intereses comunitarios, ejerce funciones públicas delegadas por la ley. Incluso, el patrimonio que posee le perienece en propiedad para cumplir ciertos propósitos, no pudiendo transferirlo de ninguna forma, y la administración e inversión de sus ingresos tiene limitaciones legales extraordinarias.

La legislación tributaria establece quiénes son considerados sujetos para la aplicación de los impuestos a la renta y señala taxativamente qué entes societa- 
rios deben ser considerados como sujetos pasivos de este impuesto; en el inciso " $c$ " del artículo 14, se considera como personas jurídicas a las cooperativas, fundaciones y asociaciones, en lo que se refiera a las rentas no exoneradas. La norma tributaria al considerar a estos entes, cuyos fines son tradicionalmente no mercantiles, de carácter civil y de interés social, como sujetos del impuesto respecto a las rentas no exoneradas que obtuviesen, efectúa una excepción al criterio de discriminación tributaria de personalidad juridica para los efectos del impuesto a la renie. Cabe anotar sobre este punto que el Decreto Supremo No 287-68-HC al incluir como sujetos del impuesto en calidad de personas juridicas a las asociaciones, fundaciones, etc., to hizo con el propósito de evitar la evasión tributaria al gozar estas instituciones de una exoneración subjetiva, y por ello, hubo de establecer la atribución excepcional de este carácter, pese a que estos entes no son sociedades de capital.

Las Comunidades Laborales revisten ciertos caracteres en su personalidad que permiten su clasificación dentro de un sector social similar al de asociaciones - cooperalivas, y de esta similitud se obtendria la errónea conclusión de tenerse a las Comunidades Laborales como sujetos pasivos de este impuesto. Tal conclusión traeria consecuencias que trataremos de examinar lo más ampliamente posible.

Es fácil advertir que si las Comunidades revisten el carácter de personas juridicas (en el supuesto de ser legal la aplicación de la norma del inciso "c" del artículo $14^{\circ}$ del D.S. No 287-68-HC), es decir de sujetos obligados al pago del impuesto a la renta, las participaciones y el fruto de éstas serán gravados como de Tercera Categoria; consecuentemente, el rédito que perciba el comunero deberá considerarse de Segunda o de Tercera Categoria, según se perciba, como dividendo o como reparto, y sufrirá la misma renta doble imposición, en la Comunidad y luego el gravamen que recae a la renta global del comunero como sujeto del impuesto a la renta de personas naturales. Este planteamiento sería aceptable juridicamente cuando la Comunidad tuviese las características que tiene una sociedad mercantil cuyo capital está representado por acciones y cuyas acciones reflejan el valor proporcional de toda la riqueza de la sociedad, cuyos accionistas son únicamente aportantes de capital (su calidad está dada y sustentada únicamente en ser titular de ese aporte).
En el manejo de la sociedad rige el principio de "una acción un voto", es decir una sociedad de capital. La Comunidad no presenta características ni siquiera parecidas, pues, como ente análogo a la asociación, las decisiones son tomadas en razón de la volunlad de cada uno de sus miembros y no por las acciones que pudiesen tener éstos (9). El que la Comunidad sea socia, accionista o participante en los réditos y manejo de la empresa que la causa, no altera en lo más mínimo estos caracteres de institución iegal de carácter no-mercantil.

En consecuencia, creemos que no es posible aplicar la norma excepcional a la Comunidad, por cuanto no se encuentra, ni por su origen ni por su naturaleza legal, en análoga situación jurídica de aquellos entes que el inciso "c" considera.

Claro está que, pese a cualquier similitud entre la Comunidad Laboral y estos entes, no significa que, en razón de posible analogía, se puede considerar a la Comunidad como sujeto pasivo del impuesto a las personas juridicas por aplicación del inciso "c" del artículo 14 을 del Decreto citado.

Como ya hemos visto al tratar sobre el concepto de sujeto pasivo, en algunos casos tienen estos entes de hecho (o sea estas personas colectivas que no revisten los caracteres típicos de personas juridicas para efectos tributarios) carácter de sujetos pasivos en la obligación tributaria cuando la norma tributaria expresamente les asigna ese carácter, esa capacidad de ser titular del patrimonio que detenta 0 de la renta que percibe. Es así que sólo se puede considerar a entes tales como la asociación o las cooperatives sujetos pasivos en una obligación tributaria determinada, cuando la ley tributaria les reconoce o les atribuye expresamente tal calidad. Este es el caso del inciso "c" del artículo $14{ }^{\circ}$ del D. S. № 28768-HC. Téngase presente que sólo serán considerados como sujeto pasivo respecto a rentas del comercio o la industria.

Entonces, si de acuerdo a las reglas de interpretación del Derecho Tributario el sujeto pasivo de la obligación en cuestión, esto es, la del impuesto a la renta, se determina por la calidad expresa que el sujeto debe tener de "deudor del impuesto", es decir que tenga el carácter de contribuyente por deuda propia

9. Art. $31^{\circ}$ del D. L. $N^{\circ} 18384$; art. $191^{\circ}$ del D.S. No 011-71-PE. 
- que lo señala la ley como el obligado directo, y no siendo un ente de hecho con capacidad tributaria, según hemos visto en párrafos anteriores, la conclusión es muy clara: la Comunidad Laboral no puede ser considerada como el sujeto pasivo de la obligación tributaria en el impuesto a la renta.

Ahora bien, esto nos lleva a señalar que, aplicando el criterio de las normas tributarias referentes a las personas colectivas que no tienen capacidad tributaria para ser sujetos pasivos, las rentas que obtenga la Comunidad deben atribuirse a sus miembros, aplicando, pues, la norma que contiene el art. $14{ }^{\circ}$ en sus dos últimos párrafos.

Este criterio no parece del todo adecuado para el caso que nos ocupa, pues es obvio que la referida disposición legal no tenía prevista semejante situación legal, y esto, por la sencilla razón de que los conceptos empleados por el legislador en estos dos últimos párrafos del art. $14{ }^{\circ}$ y en muchas otras disposiciones conexas, no corresponden de ningún modo al concepto de Comunidad Lboral, concepción totalmente nueva y de naturaleza sui generis.

Las diversas rentas comunitarias que percibe la Comunidad Laboral podrian distinguirse en dos grandes grupos: las legales y las naturales o producidas por la colocación de capitales (reinversión o inversión).

Las legales son aquéllas que las leyes de la materia señalan como porcentaje fijo de la renta neta de las empresas: en los sectores pesquero, minero y de telecomunicaciones, estas rentas legales incluyen el porcentaje sustitutorio de la participación de utilidades de la ley № 11672, porcentaje que también es denominado como participación líquida, no así en el caso de las Comunidades Industriales, pues el porcentaje de participación líquida debe ser entregado directamente a los trabajadores, sin intervención alguna de la Comunidad.

Respecto a este porcentaje de la renta de la empresa que tiene carácter de participación sustitutoria del arterior régimen sobre participación de las utilidades, no existe problema de aplicación, estando expresamente señalada por la ley como un beneficio social, sea cual fuere el sistema o modo de su percepción por los comuneros.

No ocurre to mismo respecto al porcentaje de las rentas legales que se denomina "participación patrimonial", pues la ley no le atribuye categoría y tal por- centaje se traduce en adquisición de bienes de capital en la mayoría de los casos, por lo que si se prescinde del aspecto subjetivo podríamos decir que se trata de una corriente colocación de capitales. Es sobre esta renta destinada a la reinversión o inversión y sobre los réditos que tales colocaciones produzcan los hemos denominado como "réditos naturales" o "propios", que se plantea visiblemente el problema de la categorización y aplicación del impuesto a la renta, según el régimen tributario vigente.

Para esto, debemos tener presente que en todos los sectores de participación comunitaria, con excepción (que probablemente no subsista for mucho tiempo) del sector industrias, existe el sistema compensatorio, el cual implica que una fracción de la participación patrimonial sea aportada a la Comunidad de Compensación y que por esto, la renta comunitaria provenga de bienes propios de cada Comunidad Laboral y de las acciones que tenga en el patrimonio de la Comunidad de Compensación.

Entonces, tenemos que clasificar los ingresos provenientes de la participación comunitaria en los siguientes:

19 Participación líquida o sustitutoria del beneficio social denominado participación en las utilidades (Quinta Categoria)).

20 Participación patrimonial que constituye el porcentaje de la renta neta empresarial destinado a la inversión o la reinversión, según los casos, $y$ que en los sectores donde existe sistema compensatorio, parte de los bienes de capital adquiridos con dicha renta legal son aportados a la Comunidad de Compensación respectiva, por lo que se debe distinguir dos subclases de bienes productores de renta natural: a) acciones, bonos y participaciones de la Comunidad laboral cuyos réditos irigresan a ella para su distribución (parcial y/o total) entre sus miembros, y b) acciones de la Comunidad de Compensación del sector a que pertenezca, cuyos réditos ingresarán al fondo de la Comunidad Laboral para luego ser repartidos conjuntamente con otros frutos.

$3^{\circ}$ Réditos naturales son los dividendos, intereses, paricipaciones y dietas que se gereran de la participación patrimonial en sus dos formas indicadas, una proveniente de los bienes propios, - sea de la participación en el patrimonio empresarial o valores mobiliarios que tuviese la Co- 
munidad Laboral, y la otra (que se da en los sectores con sistema compensatorio) rentas como dividendos de acciones que haya recibido la Comunidad Laboral de la Comunidad de Compensación. Estas acciones de la Comunidad de Compensación representan todos los valores de inversión o reinversión aportados por el conjunto de Comunidades Laborales del sector respectivo, por lo que aquellos dividendos que se entregan según las acciones de Comunidad de Compensación vienen a ser, en buena cuenta, la redistribución de los réditos de varias clases que se atribuyen a este sistema en relación a los aportes mobiliarios efectuados.

Las rentas naturales son aquéllas que provienen de la reinversión capitalizada o de la inversión en acciones $\mathrm{y} / \mathrm{o}$ bonos, bienes que producirán un rédito, sea utilidad o dividendo o intereses. Estas rentas de bienes que la Comunidad detenta o posee como patrimonio comunitario están sujetas al impuesto que coresponda, sin lugar a dudas, pues no están exoneradas.

El problema que se plantea, pues, en este tipo de rentas que llamaremos "propias" o "naturales", es cué Categoría atribuirles, pues se presentan en varias formas pero con el mismo sujeto pasivo o contribuyente y por la misma razón o fundamento, mejor dicho, por la misma causa juridica.

\section{b) Aplicación del impuesto}

Entramos ahora al examen de cómo se aplicaria el régimen impositivo a los réditos comunitarios, debiéndose tener presente que consideramos inapropiada la iplicación de este régimen vigente a tan imprevista siluación juridica y real, porque el sistema previsto en e) Decreto Supremo No $287-68-H C$ y sus modificatorias y reglamentos no contempla en absoluto el nuevo régimen de participación de los trabajadores en los beneficios de las empresas; sin embargo, es evidente el criterio oficial de aplicar a esta nueva situación el sistema vigente en base a considerar a la Comunidad Laboral como una sociedad sin personalidad jurídica para efectos del impuesto o como una comunidad de bienes, con la consecuencia de que las rentás que obtenga deberán ser atribuidas a las persoras naturales que la integran. De tal modo que analizaremos la aplicación del sistema impositivo vigente bajo esta premisa, pero con el propósito de manifes- tar lo injusto y contradictorio a la real naturaleza del hecho imponible.

Sobre las rentas legales que percibe la Comunidad, debemos distinguir que, respecto a la denominación "liquida" sustitutoria de la participación de utilidades otorgada por la ley $N$ o 11672 , se aplicará el régimen de Quinta Categoría (10); y sobre el porcentaje que se denomina "participación patrimonial", el cual está destinado a la reinversión en la propia empresa o en valores de instituciones financieras, no habria gravamen, en principio, pues este porcentaje se halla expresamente exonerado (11), aun en el caso de la Comuridad Industrial cuando ya se haya alcanzado el $50 \%$ en propiedad del capital social de la empresa (12), pues tal aporte ingresa al Fondo Ordinario de la Comunidad para ser distribuido como cualquier otra renta comunitaria. Debe observarse que la legislación referente a los sectores minero, pesquero y de telecomunicaciones disponen invariablemente que el porcentaje de participación patrimonial sea invertido necesariamente en valores, pese a que se haya alcanzado el $50 \%$ en la propiedad del capital.

Las exoneraciones en estos casos adolecen de falla técnica, puesto que de los textos y del espíritu de estas disposiciones se puede colegir que tales exoneraciones deberían ser permanentes o vitalicias. Sin embargo, tales exoneraciones carecen de los requisitos legales que señala el numeral VIII del Código Tributario, debiendo caducar al año de su otorgamiento.

Otro defecto de técnica que observamos es la exoneración que en algunos casos (13) se establece en forma genérica, quizá con el propósito de no dejar que esta institución social sea gravada por ningún concepto, pero a tenor de la rorma contenida en la ley específica, art. $112^{\circ}$ del D.S. No 287-68-HC, estará afecta al impuesto a la renta la inversión o reinversión del porcentaje patrimonial en los casos señalados.

En consecuencia de lo anterior, tenemos que, en la mayoría de los casos, estará gravada la percepción

10. D.S. No $171-\mathrm{EF}$, art. $1^{0}$ (interpretativo del art $17^{\circ}$ del reglamento de D.S. No 287-68-HC).

11. D. L. No 18350 , art. $24^{\circ}$; D. L. No 18384 , art. $16^{\circ}$ y 19, inc. “a”-2; D. L. $\mathrm{N}^{\circ} 18810$, art. $74^{\circ} ;$ D. L. N" 18880 , art. $285^{\circ}$; D. L. No 19020 , art. $98^{\circ}$ '

12. D. L. No 18384 , art. $19^{\circ}$ inc. “a”- $2^{\circ}$.

13. D. L. $\mathrm{N}^{\circ} 18810$, art. $74^{\circ} ;$ D. L. $\mathrm{N}^{\circ} 18880$, art. $285^{\circ}$; D. L. No 19020 , art. $98^{\circ}$. 
del porcentaje de participación patrimonial, sea en forma de acciones de la empresa por efecto de reinversión o la adquisición de títulos valores, cujáa inversión no está exonerada.

Veamos, entonces, qué régimen tributario es aplicable a estas inversiones capitalizables efectuadas en la empresa a la cual pertenece la Comunidad. En primer término, se aplicaría el régimen especial del llamado impuesto a las capitalizaciones y este consiste en la aplicación del art. $77^{\circ}$ del D.S. No 287$68-\mathrm{HC}$, que prescribe un impuesto definitivo del $15 \%$ sobre el monto de la renta capitalizada dentro de los seis meses de cerrado el balance y siempre que fuera asumido por la sociedad con cargo a reservas de libre disposición. En este caso, no hay lugar a impuesto a la renta sobre los réditos en especie que reciben los accionistas.

Consideramos también dentro del régimen especial del art. $77^{\circ}$ del Decreto la capitalización que incluso está contemplada por la Ley de Comunidades Industriales (14) y que es consecuencia de la reinversión efectuada por la empresa en otras. En esta capitalización se pagarán los impuestos correspondientes según la misma ley, por lo que si se efectúa dentro del plazo del art. $77^{\circ}$ y el impuesto es asumido por la sociedad (empresa) con cargo a reservas de libre disposición, no habrá lugar a impuesto alguno adicional por esta adquisición de capital que se considera en el régimen vigente como un dividendo en acciones. La consideración obedece a presumir que la sociedad está obligada a capitalizar dentro de los seis meses esta clase de reinversión, por el sentido de la norma del iriciso "c" del art. 16\% del D.L. № 18384 , y porque la Comunidad así debe exigirlo a la empresa en resguardo de sus intereses. De otro modo se la aplicaria el régimen común a que se refiere en art. $81^{\circ}$ del Decreto, esto es, de la aplicación de la tasa normal del $25 \%$ como pago a cuenta del impuesto a la renta, que en lo referente a dividendos, no debe exceder del $30 \%$ (15).

Es de mencionar también que, en lo referente a las capitalizaciones dispuestas por el D. L. № 18815 por el monto de los excedentes de revaluación de activos fijos de las empresas, las Comunidades Labora-

14. D. L. No 18384 , art. 16 , inc. "c".

15. D. L. No 18697 , art. $1^{\circ}$ sustitutorio del art. $58^{\circ}$, inc. "b" del D. S. No 287-68-HC. les tienen participación que estuvo expresamente exonerada por el D. L. № 18940.

En lo que se refiere a los réditos producidos por las acciones de la Comunidad en la empresa, a estos dividendos se les aplicaría el sistema establecido en el art. $82^{\circ}$ del Decreto en su inciso " $b$ ", por lo que la sociedad, al momento de distribuir los dividendos correspondientes a la Comunidad, deberá retener el $25 \%$ de los mismos como pago a cuenta del impuesto a la renta de los beneficiarios, esto es, de los comuneros. Pero, conforme a los artículos $62^{\circ}$ y $64^{\circ}$ del mismo Decreto № 287-68-HC, tal renta de Segunda Categoria se considera percibida cuando se pone a disposición de los integrantes de la Comunidad. Lo mismo ocurre cuando se trate de intereses de bonos que no estuviesen exonerados, por ser réditos de Segunda Categoria, los que se consideran percibidos cuando estén a disposición de sus beneficiarios. La percepción de estos réditos se entenderá, pues, producida cuando la Comunidad, de acuerdo a los disposiciones que la rigen y conforme a las condiciones específicas que señala la ley, distribuya estos dividendos e intereses a los comuneros, los que deberán tomar en cuenta la retención efectuada en la fuente, para efectos de determinar el impuesto global a la renta que les pudiese corresponder, sino 10 más probable que la mayoría de los comuneros no deba pagar impuesto alguno por no obtener monto gravable, produciéndose por tanto un derecho a solicitar la devolución del importe retenido en la fuente, esto sin perjuicio de lo dicho sobre la improcedencia de aplicación del sistema actual de imposición.

Respecto a las participaciones en las utilidades que provengan de la participación en el capital de la empresa que constituye una sociedad sin capital accionario, de acuerdo al criterio de categorización, tales utilidades serian de Tercera Categoría, y por tanto, se las consideraría distribuidas al término del ejercicio entre los socios y en el caso de la Comunidad, socia de este tipo de empresas, estas utilidades que le tocan deberian considerarse como percibidas por sus miembros automáticamente (16).

La aplicación de las normas citadas para esta clase de sujetos, los comuneros, significa en buena cuenta que éstos declaren como percibido un rédito que,

16. Arts. $28^{\circ}, 62^{\circ}$ inc. "a” y $75^{\circ}$ del D. S. N $N^{9} 287-68-$ HC. 
ciencia cierta, no pueden determinar en su cuantía, debido a que el sistema comunitario de distribución de utilidades provenientes del capital está reglamentado con un criterio totalmente incompatible con la atribución automática a sus miembros. Puesto que el comunero recibirá este tipo de réditos en razón a normas especiales, tales como el requisito de labor real y efectiva por un período mínimo y la percepción de tales réditos en dos formas, el $50 \%$ a prorrata y el otro tanto en razón al tiempo de servicio como comunero (17), además de no contemplarse la posibilidad de la participación compensatoria.

Es, pues, evidente la incompatibilidad en la aplicación del sistema actual de atribución de esta categoria de rentas con el sistema legal que prescribe las leyes de Comunidades Laborales, por lo menos en lo que se refiere a la distribución de estos réditos en la etapa previa a la emisión de acciones comunitarias, emisión que tendrá lugar cuando la Comunidad Laboral obtenga el $50 \%$ de la participación del capital de la empresa, y aun cuando alcanzada la etapa de distribución de los beneficios como "dividendos" de acciones comunitarias, la aplicación del sistema vigente sería desventajosa e irreal porque la distribución de los réditos que fueron generados en la fuente y entregados a la Comuridad previa retención en los casos pertinentes, no serán întegramente distribuidos entre los comuneros, puesto que la Comunidad debe reservar porcentajes de estos réditos para fines sociales y culturales, asi como sufragar los gastos de su actividad representativa; por tanto, lo que según las normas de atribución debe recibir cada comunero es diferente a lo que realmente recibirá y el porcentaje de impuesto retenido en la fuente no guarda proporción con el monto a distribuirse entre los comuneros, por lo que puede advertirse que ese $25 \%$ retenido a los dividendos, por ejemplo, al momento de prorratearse el pago a cuenta resultará que en proporción con lo que realmente se recibe por cada comunero es mucho mayor.

Ahora bien, si tratamos el caso de la mayoría de Comunidades Laborales, las que no sólo están sujetas al sistema antes referido, sino también al sistema compensatorio en la participación patrimonial y los frutos de la misma, tendremos aun mayores dificultades

17. D. L. No 18384, art. $14^{\circ}$ inc. “c”; D. L. No 18350 , art. $27^{\circ}$; D. L. No 18810 , art. 96\% ; D. L. No 18880 , art. $305^{\circ}$; D. L. $\mathrm{N}^{\circ} 19020$, art. $120^{\circ}$. y problemas insolubles sobre la atribución de las rentas, el carácter de las exoneradas, las retenciones efectuadas, etc.

Veamos sobre lo referente a las exoneraciones, puesto que éste es uno de los aspectos más importantes en las rentas comunitarias, si se considera que por un lado el legislador ha concedido exoneraciones en razón de la titularidad de la Comunidad en algunas rentas, y por otro, ha dispuesto que las inversiores o reinversiones obligatorias se efectúen en valores que gozan de exoneración.

Según el sistema impositivo en vigencia, los sujetos pasivos están obligados a declarar todas las rentas que obtuviesen aun las exoneradas, de tal modo que, respecto a los comuneros, se presenta el problema inscluble de la determinación precisa de los réditos exorierados que le corresponde atribuirse como percibido, puesto que, como hemos señalado repetidamente, el rédito que percibe el comunero por participación en la renta comunitaria, es decir en la parte del Fondo Ordinario que se repartirá anualmente, tiene una sola naturaleza o denominación y no podría discriminarse qué porcentaje de este rédito corresponde a dividendos o intereses exonerados, lo que en gran mayoría de casos ocurre, pues, en las Comunidades de todos los sectores, el legislador ha dispuesto la inversión del porcentaje de participación patrimonial en valores de COFIDE, cuyos réditos están exonerados.

Además, en lo que respecta al sistema compensatorio, la redistribución de los aportes patrimoniales integrados en muchos casos por títulos valores que representan reinversiones exoneradas, no podrán discriminarse cie aquéllos que no lo están, puesto que la Comunidad de Compensación por todos los valores que reciba, emitirá acciones representativas de ese patrimonio, distribuyéndolas entre las Comunidades miembros, por lo que no sería posible distinguir qué réditos de dichas acciones de compensación proceden de títulos valores exonerados, y que por lo mismo, sus réditos están exonerados.

Según la legislación de la materia, parte considerable de las rentas comunitarias denominadas "naturales" (para distiriguirlas de las legales) en los sectores en que existe el sistema compensatorio, corresponde a la Comunidad de Compensación, con cargo a la distribución en base a criterios especiales. Estas rentas naturales que entran en el sistema de compensación 
pueden ser también exoneradas o no, según la fuente de que procedan, y por obra de la redistribución compensatoria a que son sometidas, se nos presenta el mismo problema de distinguir qué porcentaje de las mismas son exoneradas cuando son repartidas como dividendos de las acciones de la Comunidad de Comperisación a cada Comunidad Laboral y más aún, cuando son percibidas por cada comunero.

De otro lado, de acuerdo a la función compensatoria que ejecuta la Comunidad de Compensación al redistribuir todas las rentas obtenidas a través de todas la Comunidades Laborales del sector a que pertenezca, resulta que cada comunero podría recibir una renta mayor o menor a la que le tocaría según el ingreso total de su Comunidad Laboral, pues bien, en el suipuesto que se hubiese retenido en la fuente el $25 \%$ por dividendos y éstos correspondan a la Comunidad de Compensación por ser ésta la titular de las acciones, se nos presenta la imposibilidad de poder determinar cuál sería esa renta en dividendos que, redistribuida conjuntamente con otras de diversa categoría y que pudiesen estar exoneradas, es percibida finalmente por el comunero, quien es en definitiva el sujeto pasivo del impuesto a la renta.

En consecuencia, el comunero, quien resulta el auténtico sujeto pasivo en el impuesto a la renta comunitaria, se hallaria en la imposibilidad de declarar los diferentes réditos provenientes de la participación patrimonial y su cuantía, así como deducir las rentas exoneradas que reciba de la Comunidad Laboral y de la Comunidad de Compensación, a través de la primera.

La improcedencia, por lo injusto e inadecuado de aplicar el sistema vigente a los réditos comunitarios, toma mayor relieve e importancia si se consideran las caracteristicas, condiciones y el peculiar sistema legal establecido por las leyes de Comunidades Laborales. En el sistema de participación comunitaria, el comunero percibe dos tipos de renta, una correspondiente a la participación líquida y la otra constituida por la participación patrimonial. Dentro de esta última se pueden dar varias clases de rentas, tales como dividendos, en especie y dinero, intereses o simples utilidades, pudiendo tener el carácter de exoneradas, según la fuente de que provengan. El sistema actual de imposición a estas clases de renta prevé tratamientos distintos y tasas diferentes, pero en el sistema comu- nitario la percepción de estos réditos de la participación patrimonial por parte del comunero, no admite discriminación respecto a qué porcentaje de lo que él recibe corresponda a qué clase de rédito o al carácter de exonerado que pudiese tener.

Finalmente, y pese a nuestra atingencia sobre lo improcedente del actual régimen a este sistema de participación de los bereficios de las empresas, creemos oportuno, en vía de agotar el análisis que nos hemos propuesto en este capitulo, tratar la cuestión sobre si el sistema compensatorio implica una generación de renta entre la Comunidad de Compensación y los comuneros de las Comunidades Laborales que sean miembros de aquélla. El planteamiento obedece a que como ya hemos visto, el sistema compensatorio significa aportes de valores, o sea de bienes que producen renta, de las Comunidades Laborales a la Comunidad de Compensación respectiva, la cual conforme a su función legal, percibe los réditos de que generan estos aportes y los redistribuye entre todas las Comunidades Laborales aportantes.

El análisis de este mecanismo arroja como resultado que las rentas redistribuidas por la Comunidad de Compensación son las mismas que produjeron por la colocación de capitales que ésta mantiene en su poder en mérito a los aportes indicados, y en consecuencia, al redistribuirlas a las Comunidades miembros, de acuerdo al criterio de compensación, no se produce rédito alguno, no existiendo, pues, hecho imponible en la redistribución. En este sistema compensatorio se da situación parecida a la de las sociedades anónimas que perciben dividendos y que, conforme al sistema impositivo vigente, la redistribución no estará sujeta a una segunda retención, además de no ser computable para la renta de la persona jurídica.

Sin embargo, como ya lo hemos expuesto en párrafos anteriores, la operación de redistribución en el sistema compensatorio ocasiona, al integrar indistintamente diferentes clases de réditos y hasta de categorías, la imposibilidad por parte del comunero de practicar la discriminación de estas clases y categorias de rentas que reciba a través de la Comunidad Laboral a que pertenezca, lo que a su vez impide que el sujeto pasivo pueda aplicar sobre estas rentas los diversos derechos a fin de determinar con exactitud las tasas que en definitiva le corresponda abonar al fisco, de acuerdo al sistema tributario vigente. 


\section{CATEGORIA DE LA RENTA COMUNITARIA}

\section{Cuestiones previas}

Las caracteristicas fundamentales de toda Comunidad Laboral en cuanto a su naturaleza pueden resumirse en las siguientes:

1. Es una institución de interés social, pues sus fines esenciales - el beneficio laboral y la unificación o fortalecimiento de la empresa son objetivos de preferente interés para el Estado moderno de hoy. La empresa reformada con la participación laboral constituye, pues, una superestructura económica-social necesaria para un cambio que haga posible el desarrollo integral y masivo de la producción, de las colectividades productoras que son el sector más importante del país.

2. Es una persona moral que representa los interesese colectivos de los trabajadores permanentes y reales de una empresa, y esto se traduce en ser la socia legal para efectos de la participación y para el ejercicio de los derechos derivados de ésta: cogestión, propiedad sobre el capital y percepción de las utilidades.

3. Es uria entidad de beneficio laboral, por cuanto dentro de sus fines esenciales está el de distribuir y compensar a los comuneros (trabajadores reales y estables), en razón a su trabajo, categoría laboral y tiempo de servicios, etc., con el patrimonio que posea de acuerdo a las leyes respectivas.

Esta primordial característica para los efectos de la presente tesis la sustentamos en las siguientes consideraciones.

Partiendo de la premisa que la prestación de trabajo subordinado es una actividad social; que la misma se da en una organización de factores interdependientes: capital y trabajo, los que constituyen la empresa, (unidad de acción que los integra); y que el factor trabajo consiste en la aportación colectiva y organizada de un grupo de trabajadores, revelando su carácter eminentemente social; interpretamos que la participación de los trabajadores en los beneficios de las empresas es un derecho social. En consecuencia, la naturaleza jurídica de la misma es la correspondiente a un beneficio social, por lo que consideramos a tal instituto o sistema como de naturaleza laboral, y por lo mismo, sujeto a las reglas de esta rama de derecho. Pues aun si por la forma y el modo en que muchas veces adopta la aplicación legal o convencional de este beneficio, aparece como una relación de carácter comercial regida por el derecho mercantil, que presupone la igualdad de los sujetos y el interés privado de los mismos, no por esta similitud en la forma deja de tener el carácter sustantivo que le imprime la actividad laboral de la cual deriva, o por cuya razón existe, legal o convencionalmente. No puede ignorarse esta naturaleza social o laboral en la participación de utilidades que analizamos, a pesar de que en su aplicación tal beneficio revista caracteres propios de los actos o convenciones de comercio y adopte sistemas de participación iguales a los establecidos en el derecho mercantil. Ello se debe a que éstos son los únicos medios legales existentes en nuestra legislación para realizar el beneficio de participar en las utilidades, aunque no sean en la mayoría de los casos los más adecuados a la verdadera naturaleza de la participación laboral de que se trata.

Fundamentando aún más nuestra afirmación sobre la naturaleza sustantiva de la participación en las utilidades que constituye toda Comunidad Laboral, nos extenderemos sobre este punto. Así, cuando la participación consiste en compartir los beneficios mas no las pérdidas que pudiese sufrir la empresa, tenemos un típico caso en que no cabe duda de la naturaleza laboral de tal participación. Si por el contrario se trata de una participación activa y pasiva, es decir los trabajadores comparten también las pérdidas del ejercicio anterior, las que se compensarán con las ganancias posteriores, de tal modo que los trabajadores corren los riesgos del capitalista, se nos ofrece el típico caso de los socios, por lo que podriamos pensar que no se trata propiamente de un derecho emergente de la calidad de trabajador, sino en este caso se da la de accionista o socio de la empresa.

Efectivamente, toda participación auténtica en las utilidades de la empresa supone una relación jurídica de sociedad, en su concepto genérico, pues el fundamento jurídico de tal derecho social es precisamente la aportación de trabajo, factor integrado en la empresa, unidad económica, y es en razón a este aporte de los trabajadores que los mismos tienen derecho a participar en los resultados de la empresa. Pero es preciso distinguir que esta relación jurídica de socios naturales, para distinguirlos de los convencionales, tiene un carácter jurídico distinto al de estos úl- 
timos, es decir son socios porque su labor dentro de la organización de la empresa es un verdadero aporte de trabajo al fin u objeto de ésta, y en esto estriba el carácier de socio industrial, es decir de aquél que pone conocimiento o esfuerzo, labor física o intelectual en una empresa.

A esta consideración debe añadirse que el aporte de trabajo se hace colectivamente, en calidad de clase trabajadora, y por tanto, el aporte de trabajo tiene el carácter de aporte socia!, por lo que tiene un carácter de interés social que necesariamente debe regularse por normas de derecho distintas a las de interés privado o puramenie mercantil, ya que el titular del derecho a participar en los beneficios es un grupo de trabajadores; pues, existe el derecho social a la participación en tanto exista una masa de trabajadores $y$, aunque el beneficio se individualice, el derecho es colectivo. Esto se encuentra sustentado en conziderar al factor trabajo como aportación conjunta y organizada de un grupo de trabajadores, revest'do de un carácter social que le confiere importancia equivalerite al factor capital, de alli que se le confiere el derecho a participar y el especial tratamiento jurídico de éste y sus efectos, así nos lo indican las múltiples exoneraciones de los impuestos que normalmente afectaría la percepción de estos beneficios, tanto en la legislación vigente como en la antecedente (18).

Por tanto, creemos que cualquier régimen de participación colectiva en las utilidades de la empresa no modifica sustancialmente la relación jurídica que la causa: el contrato de trabajo, ya que el derecho a participar surge de la calidad de trabajadores, quienes, con su aporte en colaboración con el capital, producen la riqueza o beneficio de la empresa de la cual forman parte. No puede confundirse lo anterior con la relación jurídica del contrato de sociedad, pues éste implica la "affectio societatis", la convención con el ánimo de lucro.

Debe distinguirse que en la participación de los trabajadores, la causa jurídica de tal beneficio es el principio equitativo de complementar las remuneraciones básicas o minimas con una adicional que esté en relación directa con los beneficios obtenidos por la em-

18. Las exoneraciones del impuesto a la renta a los beneficios de la participación en las utilidades en el régimen anterior al D.S. No 171-EF, a los impuestos de registro y timbres por D. L. No 19480, artículo úrico. presa, los cuales, como hemos dicho, se deban a la aplicación conjunta y organizada de capital y trabajo.

Es necesario señalar que doctrinariamente la participación de los trabajadores en los beneficios de la empresa casi siempre se ha considerado como una forma especial de retribución, es decir como un salario adicional.

En conclusión, podemos agregar que la participación en las utilidades es social cuando la relación jurídica tiene como sujeto activo a un grupo de trabajadores, puesto que tal derecho les ha sido conferido o reconocido, sea por disposición legal o pacto, en razón de constituir una clase trabajadora, no lo es cuando la participación se establece individualmente, mediante contrato de asociación en participación, relación jurídica que no tiene, pues, carácter laboral.

$Y$ reforzamos lo dicho en la doctrina consagrada respecto a la naturaleza de beneficio laboral que implica un sistema de participación en las utilidades de las empresas. Asi, tenemos al tratadista español Hernainz Márquez, quien se ha ocupado extensamente sobre este beneficio, al cual denomina sistema, clasificando sus variedades o formas, sea por el motivo que le da origen: discrecional, contractual o legal; por si su aplicación es exclusiva o no para retribuir el trabajo: total o parcial; por si la cuantía de la participación esté fijada de antemano o a determinarse una vez obtenidos los bereficios de cada ejercicio. También clasifica al sistema de participación por el modo activo, o activo y pasivo; esto es si sólo se participa en las ganancias o también en las pérdidas de la empresa, lo cual tiene como consecuencia que ejercicios de pérdidas puedan ser compensados con los de ganancias.

Reproducimos el párrafo referente a la última clasificación, pues lo consideramos de suma importancia:

"Aludamos, por último, a una interesante clasificación que separa la participación inmediata y la diferida. En la primera, una vez ultimado el balance, se hace entrega a los trabajadores la cantidad en metálico que les corresponda, mientras que en la diferida, el activo a su favor se aplica, bien a instituciones de previsión o ahorro, o revistiendo la interesante forma especialmente defendida a comienzos de este siglo en Francia y Bélgica, del accionario obrero, consistente en hacer a los trabajadores titulares de parte del capital de la empresa, constituidos por acciones de trabajo, cuyo importe se ha satisfe- 
cho precisamente con los beneficios por él obtenidos" (19).

Es a esta clasificación que correspondería el sistema adoptado por el legislador peruano mediante el establecimiento de Comunidades Laborales, pero con diferencias y caracteres adicionales, tales como la coparticipación en la gestión empresarial, por lo que si bien es cierto que recoge los lineamientos básicos, la clasificación citada, este sistema, en parte inmediato $\mathrm{y}$ en parte diferido, tiene modificaciones sustantivas, tales como la titularidad del derecho sobre parte del capital a la Comunidad y no a los trabajadores, con la consecuencia de ser la Comunidad como ente colectivo quien participa en la propiedad del capital de la empresa, la gestión y los beneficios de la misma.

El sistema de participación en los beneficios de la empresa mediante el sistema de Comunidad Laboral difiere, pues, del arriba tratado por Hernainz Márquez, y no cabe duda que es totalmente nuevo en cuanto a sistema, pues conteniendo elementos ya consagrados en otras legislaciones, integra éstos (modificados) con otros que le confieren una naturaleza jurídica sui generis que no tiene antecedente alguno.

El nuevo sistema impuesto por el legislador actual no sólo persigue una participación en los beneficios - utilidades de la empresa, sino también una activa participación canalizada en la gestión, el manejo, la dirección de la misma, elemento que produce en las empresas de los sectores en los cuales se aplica una transformación de gran trascendencia, una radical transformación de las condiciones jurídicas de los factores que intervienen en el proceso de producción, los que otrora desempeñaban roles independientes, cuyos fines eran totalmente distintos: el trabajador, obtener un salario; el capitalista, lograr el mayor rédito neto posible de su inversión.

Al imponer la co-gestión de la Comunidad Laboral en el manejo de la empresa y otorgarle el medio legal (la adquisición de partes del capital hasta un $50 \%$ ), de obtener en proporción a su participación patrimonial en el capital beneficios producidos por la empresa de la cual forma parte activa, el sistema unifica intereses totalmente ajenos anteriormente, y ello prodıce una dinámica eficiente en la empresa la que,

19. HERNAINZ MARQUEZ, Miguel. Tratado elemental de derecho del trabajo, página 919, sexta edición. Instituto de Estudios Políticos, Madrid, 1953. lógicamente, producirá rendimientos muchos más altos. El propósito del sistema mediante Comunidades Laborales no sólo es lograr una real participación en las utilidades, también, y esto es más importante desde un punto de vista social y político, es lograr una participación en el capital y en la dirección de la empresa.

Pues bien, estas características esenciales de la Comunidad Laboral nos revelan una institución de carácter representativo y de beneficencia laboral. La representación consiste en ejercer los derechos colectivos de aquellos trabajadores a quienes beneficia y para quienes administra el patrimonio que detenta.

Pero la representación que desempeña la Comunidad no significa en modo alguno que podamos considerar que los derechos de propiedad sobre el patrimonio que tiene toda Comunidad, no sean realmente ni jurídicamente derechos de dominio, si analizamos la legislación de la materia encontraremos que toda Comunidad tiene en propiedad el patrimonio que reciba conforme al régimen prescrito para ellas. Esto se demuestra sencillamente con recordar disposiciones legales sobre la intrasmisibilidad por convenio de las participaciones en el capital o de los bonos y otros valores que se adquieran con el porcentaje respectivo, y en disposiciones que prohiben la reducción del porcentaje de participación en el capital, lo que significa que aún en los casos extremos de cese masivo de comuneros (cuando no se trate de disolución de la empresa) la Comunidad no puede disponer de ese patrimonio constituido por acciones o valores que representan su participación en el capital o en aquellas inversiones que señala la ley, para compensar a los miembros cesantes; para tal fin debe emplear el Fondo Ordinario o el Fondo Excepcional y dicha compensación tiene como límite el $50 \%$ de los recursos disponibles del fondo (20). Y esta regla que demuestra la intangibilidad de la propiedad otorgada a la Comunidad se repite y queda confirmada con la disposición del art. 19 \% del D. L. № 18977 que regula el caso de retiro masivo de comuneros por traslado de la empresa; en tal caso se computará para la compensación el valor total de los bienes de capital y si no fuese suficiente la mitad del Fondo para compensar a los cesarites, la Comunidad deberá obtener el dinero necesario para ello del Banco Industrial del Perú, median-

20. Art. $305^{\circ}$, inc. b del D. L. $N^{\circ} 18880$; art. $96^{\circ}$, inc. b del D. L. N 18810. 
te préstamos con garantía de estos bienes que deten$\tan$ en propiedad.

De lo expuesto se arriba a incuestionable conclusión: la Comunidad Laboral tiene el dominio sobre los bienes 0 valores que reciba conforme al régimen legal aplicable, y los comuneros miembros de la misma no pueden ser considerados como los propietarios pro-indiviso de tal patrimonio. Ahora bien, este derecho de propiedad que tiene la Comunidad está sujeto a un régimen especial y en razón a sus funciones, como toda persona moral cuya capacidad de ejercicio está determinada por el objeto o fin para el cual han sido constituidas (21).

Si enfocamos el análisis desde la perspectiva del comunero, encontramos que éste no tiene la calidad tradicional de asociado, puesto que el régimen legal le atribuye derechos a percibir los beneficios que la institución le otorga siempre que posea requisitos que son propios de la relación con la empresa, su principal. De modo que no se da un status corriente a la institución y sólo respecto a ella. Ya hemos visto que para gozar de la calidad de comunero y los derechos que de la misma se derivan, es necesario que se cumplan una serie de condiciones ajenas ciertamente a las relaciones entre la Comunidad y el comunero. Estas condiciones se refieren a la prestación de servicios, es decir al trabajo realizado en relación de dependencia funcional, considerando la prestación en forma objetiva independiente incluso de la relación formal que pueda tener, pues se atiende más bien a sl la prestación es estable, real y efectiva a tiempo completo, respecto a la actividad para la cual se ha instituido el beneficio de la partipación. A tal punto que la ley (22) confiere la calidad de comunero a los ser-

21. Tengamos presente que, respecto a las personas morales, rige el principio de la especialidad respecto a sus derechos. Esto significa que cada persona moral tiene un estatuto de acuerdo a sus fines u objetivos. (Ver PLANIOL y RIPERT, Derecho Civil Francés, páginas 77 y ss.).

22. Art. $52^{\circ}$ del D. L. $\mathrm{N}^{\circ} 18384$ y art. $173^{\circ}$ del D. S. $\mathrm{N}^{0}$ 011-71-PE.

Nota: De la redacción de las normas que constituyen las Comunidades, puede concluirse que el beneficio es para todos los trabajadores que laboran en la actividad comprendida por la ley, sin distinguir si los mismos están vinculados legalmente a la empresa de dicha actividad o no, criterio de interpretación que se confirma con la disposición anotada. vidores que formalmente laboran para patrono distinto de aquélla que es el titular de la empresa cuya actividad industria, pesquera, etc. es objeto de la prestación, por las leyes de Comunidades Laborales.

El comunero ante la Comuridad tiene derechos que provienen de la prestación de servicios y no de una relación de asociado; así, el comunero no puede pretender la percepción de renta o utilidad, cuya titularidad corresponde a la Comunidad, porque no tiene derecho, o sea, cuota, parte, acción o crédito sobre el patrimonio de la Comunidad, ni aun cuando le sean entregadas las acciones comunitarias, porque las mismas no constituyen, pese a su denominación, acciones propiamente dichas, como lo hemos demostrado ya. Unicamente, pues, el comunero gozará de los beneficios de la participación comunitaria en tanto cumpla con las condiciones de prestación de servicios calificado expresamente por la ley para merecer el beneficio. $Y$ en cuanto a la compensación al cese, ya hemos visto que ésta se recibe en cuanto se tenga la calidad de comunero que se traduce en prestación de servicios estable, real y efectiva a tiempo completo, con la limitación o tope máximo del $50 \%$ de los recursos disponibles, y esta compensación no tiene otra significación que la entrega de una suma de dinero y no de valores que conforman el patrimonio de la Comunidad, dinero que representa una participación diferida.

Si nuestro análisis anterior es correcto, entonces tendremos que considerar a la Comunidad como un ente social que, ante el impuesto a la renta, no tiene la calidad de sujeto pasivo, es decir de contribuyente directo o por deuda propia, ya quie no reviste las caracieristicas que exigen o están tipificadas en la ley para ser sujeto de la imposición a las personas juridicas. Esto ya está demostrado en nuestro análisis de la venta comunitaria. Pero, además de este último, consideramos que tampoco es procedente la aplicación de las normas tributarias que se refieren a personas colectivas sin capacidad tributaria, aquéllas a las que se refiere en penúltimo párrafo del art. $14{ }^{\circ}$ del D.S. No 287-63-HC, puesto que, como lo hemos dicho, no se puede asimilar el concepto de Comunidad Laboral con el concepto de empresas o sociedades mercantiles y aplicar la regla citada, la de atribuir a sus miembros los beneficios obtenidos, considerándolos sujetos pasivos; es en nuestra opinión totalmente contradiciorio a la real y juridica situación de los comuneros frente a su Comunidad; con el mis- 
mo sentido objetamos la aplicación del último párrafo del art. 14 ? del mencionado decreto.

En consecuencia de lo demostrado, llegamos a la conclusión de afirmar el carácter de inafecta que tiene la Comunidad Laboral frente al impuesto a la renta y que las rentas que perciba, sea cuales fueren sus categorías, no pueden atribuirse a los comuneros, ya que éstos no tienen la calidad, condición jurídica, etc. que les permita recibir por el solo mérito de estar registrado como miembro de la Comunidad las rentas que percibe esta institución.

Esto significa también considerar a las rentas obtenidas por la Comunidad como ingresos no gravables en clianto a ella y quie sólo lo serían cuando fueran percibidos realmente por los comuneros y con la categoria propia de la naturaleza jurídica de la causa de tales percepciones.

\section{CATEGORIZACION}

Con los elementos de juicio y premisas anteriores, podemos ya advocarnos a definir la categoría auténtica de la renta comunitaria que no es sino la participación colectiva en los beneficios de la empresa, participación que constituye jurídicamente un beneficio laboral.

Además de la renta comunitaria denominada "participación liquida", la cual tiene expresa categorización legal al designarla como la sustitutoria del impropio sistema de parlicipación en las utilidades existente en nuestra legislación laboral, consideramos también a todas las participaciones en las utilidades de la empresa, tanio la inmediata como las diferidas de igual naturaleza, y por tanto, de la misma categoría para efectos del impuesto directo y personal.

Como ya se ha visto al analizar las relaciones jurídicas de la Comunidad con los comuneros y con la sociedad dueña de la empresa en el Capitulo l, es en virtud al real y efectivo aporie de trabajo que un grupo de trabajadores efectúan en forma estable o permarente en una empresa que la ley otorga las participaciones en las utilidades netas de ésta. Como consecuencia necesaria de la participación legal de tipo patrimonial, se adquieren bienes que por su clase producen réditos fijos o variables; a estas rentas las hemos llamado "naturales" para distinguirlas de las "legales", pero ro deje dejarse de tener en cuenta que las primeras son consecuencia de un tipo de participación legal: el patrimonial.

Estas rentas naturales, consecuencia necesaria de la pariicipación patrimonial, tienen el mismo carácter de beneficio social, mejor dicho, de retribución equitativa al factor trabajo en la producción. La afirmación que aniecede se basa en el argumento siguiente:

Es ciaro que objetivamente la renta producida por los bienes comunitarios sea clasificable como de Segunda o de Tercera, pero sería cometer un error considerar tales rentas desde su aspecto objetivo o formal, pues el impuesto a la renta es una imposición personal que recae sobre las rentas de un sujeto y de un sujeto físico como regla general. Por ello, es necesario atribuir una renta determinada a un sujeto y luego clasificar dicha renta en función del sujeto que la percibe. Esto quiere decir que habrá que considerar la actividad, la relación jurídica, la causa y el porqué que forman parte del hecho imponible. Hay que interpretar funcionalmente el hecho al cual se debe aplicar la legislación tributaria:

Se encamina la Teoría de la Interpretación Funcional a descubrir el porqué en vez del cómo de la ley, es decir la ratio legis. Resulta, pues, que en este trabajo interpretativo se plantea si el fondo del problema se encuentra en la determinación de lo imponible y la aplicación del impuesto (apreciación técnica) o en la naturaleza dei hecho económico, o en principios políticos, que pueden aclarar los limites del hecho imponible (23).

Atendiendo a la realidad económica, la causa de la fuente productora y su porqué, la calidad del beneficiario y la causa o condición jurídica recesaria para su percepción, debemos clasificar las rentas referidas en la Categoria que corresponde.

Con este criterio consideramos que la renta proveniente de la participación patrimonial es otro medio que impone la ley para determinar o fijar, quizá en forma equitativa más ajustada al concepto de participación en los beneficios, la proporción que les corresponde a los trabajadores en el producto de sus esfuerzos como socios-trabajadores de la empresa. Tales rentas por su forma $u$ origen inmediato podrian ser catalogadas sin mayor reparo como de Segunda

23. BELAUNDE GUINASSI, Manuel. "Instituciones del Derecho Tributario", Lima, 1967, página 127. 
- Tercera Categoría, pero con el criterio de interpretación funcional, atendemos esencialmente al aspecto de la condición de quién la percibe y por qué la percibe o tiene derecho a percibirla. Como se ha expliceto en páginas anteriores, el sujeto es el trabajador y las percibe cuando sea comunero (con 0 sin acciones) y siempre que cumpla con los requisitos de labor real y efectiva, durante un mínimo de tiempo (relación laboral estable).

$Y$ este criterio se fundamenta aún más cuando, del análisis del hecho imponible, esto es de la percepción del rédito comunitario por el comunero, podemos deducir que, para obtener los berieficios de la Comunidad, hay que cumplir una prestación laboral determinada y precisa, y que para establecer el monto de estos beneficios, se aplica el factor tiempo laborado (elemento que conforma el concepto de prestación laboral) y por ello, la conclusión es casi de perogrullo: el beneficio o renta comunitaria tiene como causa auténtica el trabajo en relación de dependencia.

A estos argumentos puede agregarse que la definición de la ley tributaria sobre cuáles son las rentas de Quinta Calegoría comprende a estos réditos percibidos por los comuneros, puesto que, tanto el art. $34{ }^{\circ}$ del D.S. No 237-68-HC, así como el art. 179 de su reglamento, establecen como rentas de la Quinta Categoría a todas las derivadas de la relación de trabajo o de la prestación de servicios en dependencia, y como ya hemos explicado y fundamentado, todas las sumas percibidas por el comunero tienen como causa directa la prestación efectiva y estable de servicios en relación laboral. Tan es así que en cuanto deja de trabajar, cesa su calidad de beneficiario de la Comunidad; esto es, de ser comunero, subsistiendo para tal cesante el único derecho a la compensación, es decir a la percepción de la participación diferida.

Sostenemos, pues, que debe tenerse en cuenta como criterio interoretativo de la categoría a que pertenecen las rentas percibidas por los comuneros, el origen o la causa de las mismas, y conjuntamente, la finalidad de las normas que las otorgaron, máxime si estas las imponen de los modos referidos no interviniendo en todo caso la voluritad de los beneficiarios. Otra razón para fundamentar este criterio es que la legislación tributaria referente al impuesto a la renta cuando se trata de contribuyentes domiciliados, clasifica las rentas en lo que se refiere a categorias, esencialmente con criterios subjetivos, es decir la ren- ta es de Quinta cuando proviene de prestación de servicios en relación de dependencia; es de Tercera cuando la percibe una persona jurídica aunque por la fuente productora o la "forma", sea de Primera o Segunda.

Además, debe tenerse en cuenta el antecedente de la legislación tributaria sobre el mismo impuesto, que consideraba expresamente a las participaciones en las utilidades que perciba el trabajador como imputables a la Quinta Categoría, es decir como parte integrante de su sueldo o salario (24).

A todas las consideraciones precedentes se une en senticio confirmatorio la disposición contenida en el inciso $\mathrm{A}$ del artículo sétimo del del muy recientemente promulgado Decreio Ley sobre el nuevo impuesto sobre las remuneraciones que lleva el número 19,839 publicado el 21 de diciembre de 1972. El anotado inciso que corresponde al precitado articulo cuya norma se refiere a las remuneraciones que no son gravadas con el impuesto a cargo de los empleadores, dice textualmente: “a) Las asignaciones anuales sustitutorias del régimen de participación de utilidades a que se refiere el artículo $7^{\circ}$ de la ley 11672 y las participaciones a los trabajadores otorgadas por las leyes sectoriales".

Si interpretamos el concepto participaciones en sentido amplio, o sea como la liquida y la patrimonial, puesto que la ley no las distingue, confirmamos nuestro criterio de considerar todas las partiaipaciones provenientes de la Comunidad Laboral, aun las que aparentemente se presentan como frutos, de una sola categoria para efectos tributarios y por supuesto de la correspondiente a las remuneraciones.

\section{REGIMEN TRIBUTARIO PROPUESTO}

Como se puede apreciar de nuestras observaciones en el Capítulo $\|$ al referirnos al régimen tributario vigente, es de urgente necesidad adecuar y legislar sobre esła nueva situación y esta nueva forma de participación, ya que no estando prevista, se produce confusiones en las que se perjudica tanto el Fisco como el contribuyente.

Por lo pronto, proponemos se legisle aclarando la calidad de inafecta en la fuente a todas las rentas

24. Art. 56 de lia Ley 7904. 
comunitarias percibidas por la Comunidad Laboral, puesto que esta institución las recibe para repartirlas y sólo cuando definitivamente se hayan distribuido a los verdaderos sujetos pasivos es que debería procederse a la liquidación del impuesto que corresponda. Para tal efecto, la Comunidad y sus personeros tienen que cumplir ante el Fisco una serie de obligaciones formales o de las denominadas de hacer tendientes a determinar a los beneficiarios de las rentas comunitarias, es decir las declaraciones sobre la distribución de los réditos a cada comunero; aparte de las obligaciores propias de la administración del patrimonio de la Comunidad ante la entidad fiscalizadora.

Respecto al sistema que deberia aplicarse a la distribución final y percepción de los frutos comunitarios, estimamos que no es conveniente establecer retención alguna, pues si bien se trata de rentas de Quinta Categoria, no se trata de retribuciones considerables y si lo fueran, podría establecerse que el patrono computara tales participaciones comunitarias a efectos de las retenciones sobre las remuneraciones mensuales - jornales que paga a los servidores comuneros, que resultaran con este ingreso adicional anual, gravados con el impuesto a la renta de personas naturales.

En cuanto al problema de las rentas exoneradas en la fliente, creemos que la solución más equitativa seria el criterio de aplicarles la Quinta Categoría por su naturaleza, pero concediendo una tasa de deducción especial, según sea la fuente de donde provenga o se genere. Así, por ejemplo, los comuneros, cuya Comunidad percibe réditos exonerados tendrán derecho a deducir en determinado porcentaje (25) las rentas que perciban pese a que como sabemos, cuando existe sistema compensatorio, puede suponerse que las rentas que se reciban por intermedio de la Comunidad no sean precisamente las exoneradas; empero, consideramos que aún asi es procedente la aplicación de la deducción, porque de esta manera, se compensaria las desventajas de la participación patrimonial impropia que casi siempre se traduce en inversiones en valores de financiación, cuya adquisición y réditos están exonerados.

La. adecuación de nuestro sistema impositivo a la nueva clase de rentas de Quinta Categoria se funda-

25. El monto y escalas al respecto requerirían un estudio propio de las ciencias auxiliares de la tributación. menta en la capacidad contributiva, principio básico de todo impuesto y especialmente referido al gravamen que nos ocupa, en el cual el concepto cobra toda su amplitud, debiéndose en consecuencia atender a sus dos aspectos esenciales, ya que se trata de una imposición directa y personal. El aspecto objetivo en el impuesto a los réditos 10 constituye el ingreso producto de una fuente, es decir la riqueza percibida en este caso. El aspecto sujetivo significa la relación de esa riqueza producida con el sujeto que la percibe; esto en el impuesto que nos ocupa involucra la situación sujetiva del contribuyente respecto a la renta. Tal situación se traduce en la valoración para efectos de la imposición de las condiciones, del sujeto pasivo, mínimo de existencia, cargas familiares, etc.

Dentro de lo objetivo en la apreciación de la real capacidad contributiva además de otros caracteres, la doctrina (26) nos señala el de la naturaleza o calidad de la riqueza imponible, vale decir el origen de la renta, y es sobre el carácter de beneficio producido por la actividad laboral que encontramos el mayor fundamento para sustentar nuestra tesis. $Y$ es principio generalizado en el derecho latinoamericano $y$ en especial en el nuestro, el tratamiento especial a todas las rentas derivadas del trabajo en atención al carácter perecedero, precario e inestable de estas rentas. En consecuencia, creemos que si está demostrado el carácter de las rentas comunitarias como beneficio proveniente del trabajo colectivo, es justo atender con un tratamiento fiscal que atienda a la real capacidad contributiva de los beneficiarios, capacidad que se determina esencialmente tomando en cuenta este carácter.

Finalmente, la categorización y régimen tributario propuesto responderian a los principios de igualdad juridica y económica ante el impuesto directo y personal por excelencia: el impuesto a la renta global de personas naturales.

Se logra la igualdad jurídica ante la imposición, pues aplicando la Quinta Categoría, los trabajadores comuneros serán sometidos al tratamiento que les corresponde a su real situación y condición, como ya se ha establecido, y económicamente gravando la percepción de las rentas comunitarias, o sea de los be-

26. VALDEZ COSTA, Ramón. "Curso de Derecho Tributario” Tomo I, Montevideo 1970; p. 137. 
neficlarios laborales, atendiendo a la capactad contributiva de cada uno de los trabajadores.

Tal justicia tributarla no sería posible con el actual régimen y la aplicación de las categorías formales $u$ objetivas sobre las rentas comunitarias, pues, es claro que, pese a tener la misma naturaleza jurídica o calidad que, como hemos demostrado provienen del trabajo, se tendría que someter a distintos tratamientos de imposición, según la fuente o forma en que se perciben y con ello, resultaría que, por el aspecto objetivo de la riqueza obtenida, unos trabajadores seria afectados con retenciones de todos modos perjudiciales y otros de la misma condición y situación no tendrian tal tratamiento en razón de diversa categoria o fuente objetivamente distinta.

\section{CONCLUSIONES}

PRIMERA.-La Comunidad laboral es una institución de Derecho del Trabajo, pero con finalidades socioeconómico y políticas, además de la primordial: el bereficio laboral.

SEGUNDA.- - La participación en las decisiones y utilidades de las empresas ejercitada por esta nueva institución constituye un sistema de beneficio laboral totalmente nuevo y avanzado sin paralelo en la legislación y doctrina nacional y extranjera.

TERCERA.-Como persona moral de derecho social, pese a la calificación legal de ente de derecho privado, tiene un estatuto que determina expresamente la capacidad de goce y de ejercicio, como sujeto, excluyéndose la posibilidad de considerar su naturaleza jurídica análoga a cualquier institución de derecho colectivo, civil o mercantil.

CUARTA.--La Comunidad Laboral es también un instrumento legal para la Reforma de la Empresa en los ssctores de actividad donde ha sido implantada, reforma que se logra con la participación ejercitada por este nuevo ente colectivo.

QUINTA.-Las funciones y relaciones de la Comunidad laboral indican el carácter sui generis de entidad encargada de cumplir funciones de interés social y público.

SEXTA.-La Comunidad laboral por las funciones legales que desempeña tiene el carácter de socia privilegiada en la sociedad mercantil dueña de la empre- sa, carácter que la ley le otorga para determinados objetivos no mercantiles que debe cumplir.

SETIMA.-Como institución de beneficio laboral tiene respecto a los trabajadores-comuneros responsabilidades de la misma naturaleza jurídica.

OCTAVA.-Como persona moral tiene derechos y obligaciones patrimoniales y extra-patrimoniales distintos y exclusivos, los que no pueden ser ejercidos ni atribuidos a sus miembros.

NOVENA.-Los comuneros no tienen jurídica ni legalmente el carácter de socios o asociados de la Comunidad laboral, son beneficiarios de ésta por su calidad de trabajadores efectivos y estables en la empresa de cuya organización forman parte.

DECIMA.--Los beneficios recibidos de la Comunidad laboral constituyen una retribución adicional a los reales y permanentes servicios en relación de dependencia funcional; retribución que significa una auténtica participación en las utilidades de la empresa. siendo pues un típico beneficio social.

UNDECIMA.-Dentro del aspecto tributario con relación al impuesto a la renta de personas jurídicas, la Comunidad no tiene la naturaleza ni otros caracteres que permitan considerarla como sujeto pasivo de este impuesto.

DUODECIMA._Las rentas legales obtenidas por la Comunidad laboral no están afectas a imposición y tampoco pueden considerarse como percibidas o atribuibles a los trabajadores/comuneros mientras éstos efectivamente no las perciban conforme al régimen de participación. Aún en el caso de réditos que objetivamente considerados sean de tercera categoría.

DECIMOTERCERA.-El hecho imponible se verifica cuando los comuneros reciben las participaciones que les correspondan en virtud a su real y efectivo trabajo durante un lapso; causa jurídica que determina la real categoría de los réditos: quinta.

DECIMO CUARTA.-Es necesario legislar un régimen impositivo referente a los beneficios comunitarios que atienda al interés fiscal y sea adecuado a la naturaleza de estos réditos, evitándose así el perjuicio irrogado a la mayoría de los asalariados, quienes por sus bajos ingresos no resultan obviamente afectados por el impuesto a la renta global de personas naturales. 